\title{
Shedding light on the use of single and multisensory cues and their effect on consumer behaviours
}

\author{
Miralem Helmefalk* \\ Department of Marketing, School of Business and Economics, Linneaus University, Kalmar, Sweden, and \\ Adele Berndt \\ Jönköping International Business School, Jönköping University, \\ Jönköping, Sweden and \\ Gordon Institute of Business Science, University of Pretoria, Pretoria, South Africa \\ *Corresponding author \\ Miralem Helmefalk can be contacted at: miralem.helmefalk@1nu.se
}

\begin{abstract}
Purpose: Retail stores are required to provide a stimulating in-store experience for customers and do this by developing various strategies. One strategy implemented by retailers is the use of sensory cues to encourage consumers to engage with the environment and the products on display and available for purchase. Conducted in a lighting department, this study considers how retailers can employ a multisensory cue, which is formed by combining three single cues to positively impact consumer behaviours - specifically time spent, touching and purchase.

Design/methodology/approach: The study comprised an experimental design, which implemented single congruent visual, auditory and olfactory cues that formed a multisensory cue. Consumer behaviour outcomes of these cues were measured using objective measures.

Findings: The results show that a multisensory cue impacts time spent and purchasing, but no evidence of it affecting touching was noted. In the case of the single cues, auditory and scent cues impacted time spent, but their effect was not to the extent of the multisensory cue, which was superior.
\end{abstract}

Research limitations/implications: The study focused on one product category within a general furnishing store, thus limiting the extent to which the findings can be generalised.

Practical implications: The effect of a multisensory cue exceeded that of single cues, emphasising the need for retailers to consider and develop a multisensory retail environment. 
Originality/value: While research into the effect of single cues on consumer behaviours has shown positive effects, research into a multisensory cue, especially in a real retail setting, is relatively scarce.

Keywords: Consumer behaviours; multisensory cues; purchasing; retailing; sensory marketing; time spent.

Type of paper: Research paper

\section{Introduction}

Recently, physical retailers' task of counteracting the development of online stores has become more complicated (Van Kerrebroeck et al., 2017). Not only do the retailers have to attract consumers into the store, but they are also required to provide an engaging in-store experience. To facilitate this, retailers design their stores to attract attention and provide positive sensory experiences (Hultén, 2012). For example, a store like Apple's iStore is constructed to encourage customers to touch the product, thereby increasing their sensory experience (Williams and Ackerman, 2011).

How retailers facilitate consumer engagement through the use of sensory cues has been extensively examined in research (Ballantine et al., 2010; Chebat and Michon, 2003; Jang et al., 2018; Skandrani et al., 2011), with the majority of studies investigating single cues - for instance, visual, auditory and olfactory cues - and how they impact consumer behaviours like general experiences, brand experiences and in-store behaviours, such as browsing, exploring and purchasing (Donovan et al., 1994; Hultén, 2011; 2012; Morrison et al., 2011). Studies have investigated how single cues like lighting modifications (Custers et al., 2010; Jang et al., 2018), music changes (Michel et al., 2017), or infusing the atmosphere with scents (Herrmann et al., 2013; Kivioja, 2017) can impact consumer behaviours, including purchasing (Helmefalk and Hultén, 2017).

Researchers have generally researched cues in isolation, adding or removing sensory cues while measuring their effects on consumers (Spence et al., 2014). However, as cues are not individual in nature (Marks, 2014), interdependent or perceived individually (Deroy and Valentin, 2011; Ramachandran and Brang, 2008; Spence and Gallace, 2011), combining them to form a multisensory cue is necessary to determine an integrated outcome. Such an integrated outcome can be used to enhance consumer experiences, emotions and various purchasing behaviours. 
Therefore, it is important to understand what cues can be combined effectively for them to impact on consumer emotions and behaviours (Mattila and Wirtz, 2001; Imschloss and Kuehnl, 2017).

With increased competition from online shopping, physical retailers continuously investigate ways to provide enhanced in-store customer experiences. This can be done using sensory cues, but how this is to be done and what cues (that is, single or a combination of cues) should be considered is unclear. As retail offerings are inherently multisensory (Rahman, 2012), the need for research in this area is emphasised (Spence et al., 2014),

Due to the importance of multisensory cues - formed through the combination of single cues the purpose of this research is to investigate their impact on consumer behaviours in a retail context.

Consequently, the following research question was developed: How does a congruent multisensory cue (comprising various single cues) impact consumer behaviours (touching, time spent and purchasing) in contrast to single cues? This is done by first examining three single cues, which were then combined to construct a multisensory cue, enabling both a contrast and comparison of their effect on consumer behaviours. From this it was possible to indicate which behaviours were influenced and how (Krishna, 2012; Spence et al., 2014).

This article seeks to contribute to two main streams of literature: retailing and sensory marketing.

In the retailing literature, few studies have addressed touch in the retail context (Abhishek et al., 2013). This accounts for the limited understanding of this behaviour in real shopping situations (Spence et al., 2014), and is an area that requires further research (Abhishek et al., 2013; Turley and Milliman, 2000; Vieira, 2013).

In the case of sensory marketing, previous research has mostly shown the impact of either single or multiple cues on purchase behaviour, and the importance of multisensory atmospheres and congruency (Spence et al., 2014; Hekkert, 2006). Moreover, while multisensory cues have been studied in various retail context (e.g. Mattila and Wirtz, 2001; Spangenberg et al., 2005) and indicated that these cues impact on time spent and emotions (Helmefalk and Hultén, 2017), these have rarely combined more than two congruent single ones together to investigate and compare the actual effects of single and multisensory cues. Furthermore, this study is able to add to the body of knowledge in regard to the effects of multisensory cues on touching and actual purchasing in real shopping situations. 
This study also advances the notion of measuring and employing three senses in contrast to two, which past studies have largely ignored. Consequently, this provides a methodological contribution as it employs an experiment implementing single cues and a multiple cue, a strategy that is not widely employed (Ballantine et al., 2010).

Practically, this study can assist furniture and lighting retailers on possible changes in cues that can be considered to impact behaviours to the benefit of both consumers and retailers.

The remainder of this research paper presents the theoretical framework and hypotheses, methodology, results and discussions. It concludes with a discussion of the theoretical and managerial implications.

\section{Literature review}

Atmospherics or sensory cues (Helmefalk and Hultén, 2017) are both widely used and studied within retail environments. In this study, three individual cues served as the focus, as these are the primary cues used in a furniture setting, specifically a lighting department. Visual (aesthetics), auditory (music) and olfactory (scent) cues were emphasised as they were practical, congruent and relevant to the context - that is, the lighting department (see Mattila and Wirtz, 2001; Spangenberg et al., 2005). The choice of these is elaborated in the Method section.

\section{Single sensory cues' effect on consumer behaviours}

Visual. These are cues that are received by the eyes and include simple physical cues like colour and light, or more complex variations, such as aesthetics and form (Jang et al., 2018; Tilburg et al., 2015; Vieira, 2010). As visual cues are the most dominant sense, most retail stores pay attention to it and these cues have been shown to impact cognition, emotions and various consumer behaviours, such as time spent, consumption, decision-making and purchasing (Clement, 2007; Custers et al., 2010; Quartier et al., 2009). For instance, Clement (2007) found that visual cues, specifically packaging, influences decision processes. With visual tracking, Clement showed how consumers' visual attention differed during five stages of the consumption process. Another example is the study of Vieira (2010) that showed how aesthetic design moderates a customer's purchase intention. The findings suggest that the interaction effect between high arousal and an aesthetically pleasing store environment has the greatest effect on purchase, time spent and satisfaction. 
Auditory. This refers to cues that are received by hearing and includes a variety of stimuli, including music (Oakes, 2007), voices and product sounds (Lowe and Haws, 2017; Wiener and Chartrand, 2014). Retailing literature has most frequently investigated music, its tempo, pitch and tonality, and how it impacts consumer arousal and its subsequent effect on behaviours, such as speed of movement, increased time spent or increased purchasing (Demoulin, 2011; Dube and Morin, 2001; Jacob et al., 2009). These distinctions are further exemplified in field experiments by Dube and Morin (2001), which showed that music perceived as pleasant impacts attitude towards the environment and personnel, and this subsequently mediates the relationship between the pleasant music and the overall store evaluation. Similarly, Demoulin (2011) employed field experiments to investigate the effects of congruent music. The study showed that congruent music impacts emotions, which in turn mediates the relationship between emotions and quality. In turn, these mediate return intention.

Olfactory. These cues refer to natural or artificial scents that may impact consumer shopping motivation, emotions and purchasing (Kivioja, 2017; Parsons, 2009; Spangenberg et al., 2006). While there is clear research indicating that scents are highly dependent on congruency (Mattila and Wirtz, 2001), research has focused on the simplicity (or complexity) of the scent (Herrmann et al., 2013) or the combination of these cues with other senses, such as the interplay between sound and scent (Crisinel et al., 2013; Mattila and Wirtz, 2001; Spangenberg et al., 2005). Mattila and Wirtz (2001) demonstrated how scents influence the evaluation of an environment. Cues that are congruent with the environment offer the greatest effect on approach and impulsive purchasing behaviours. The study by Herrmann et al. (2013) evolved the notion of the scent's complexity, showing that simple scents increased cognitive processing, which subsequently increased spending and purchasing.

\section{Multisensory cues}

When two or more cues are combined, they form a multisensory experience to evoke holistic perceptions, increase emotions and influence purchase behaviours (Imschloss and Kuehnl, 2017; Mattila and Wirtz, 2001; Spangenberg et al., 2005). For example, vision and touch together can impact how consumers perceive packaging or influence product choice positively (Streicher and Estes, 2016). Consumers evaluate, judge and behave differently to a multisensory cue, than to only single cues (Krishna, 2013; Macpherson, 2010).

When combining single cues, these need to be congruent (Mattila and Wirtz, 2001), being “[...] the degree of fit among characteristics of a stimulus" (Krishna et al., 2010, p. 410). This is because consumers prefer experiences that convey similar messages to the senses due to prior 
experience and learning (Hekkert, 2006). A multisensory cue impacts behaviours positively, including time spent (Helmefalk and Hultén, 2017; Morrin and Ratneshwar, 2000; Morrison et al., 2011).

\section{Consumer behaviours}

While in retail stores, consumers engage in several different behaviours, including touching and exploring the product range, which are perceived as integral to consumer satisfaction. This study focuses on three specific behaviours, namely touching, time spent and purchasing, as these are the most relevant to this retail context (Donovan et al., 1994; Hultén, 2012).

Touching. Regarded as a competitive advantage of bricks-and-mortar retailers when compared to online retailers (McCabe and Nowlis, 2003; Van Kerrebroeck et al., 2017), touching can lead to perceptions of ownership - an "endowment effect" (Kahneman et al., 1990). Factors influencing touching include the nature of the product (McCabe and Nowlis, 2003) and the need for touch (NFT) as a consumer trait (Abhishek et al., 2013; Imschloss and Kuehnl, 2017). There have been conflicting findings regarding the impact of touch on product evaluations and purchasing, with positive impacts (Marlow and Jansson- Boyd, 2011; Peck and Childers, 2006) or no impact reported (Grohmann et al., 2007; Peck and Shu, 2009).

Time spent and purchasing. Time spent has been used to reflect various actions, including browsing behaviour (Bloch et al., 1989) and increased time spent (Helmefalk and Hultén, 2017; Morrin and Ratneshwar, 2000; Morrison et al., 2011), thus reflecting a type of approach behaviour (Donovan et al., 1994). Although a single sensory cue influences behaviour (Helmefalk, 2016; Jang et al., 2018; Kivioja, 2017), studies have shown that the interplay between two or more senses enhances these effects (Imschloss and Kuehnl, 2017; Mattila and Wirtz, 2001; Spangenberg et al., 2005). This is because involving more senses provides more information for consumer decision-making (Macpherson, 2010), increasing the likelihood of purchasing (Krishna, 2012).

\section{Theoretical model and hypotheses}

To answer the research question, a theoretical model (see Figure 1) was developed presenting the theoretical linkages and the hypotheses. 


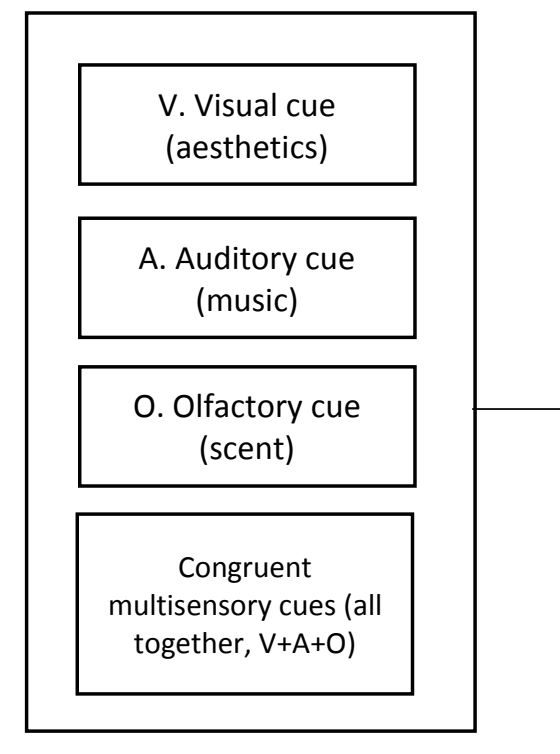

Sensory cues

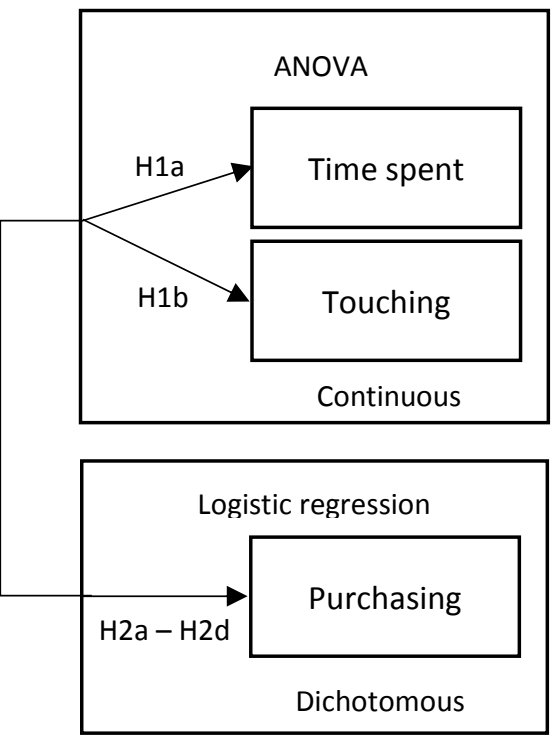

Consumer behaviour

Figure 1. Theoretical model

Single visual, auditory and olfactory cues influence the perception of time (Antick and Schandler, 1993; Helmefalk and Hultén, 2017), yet with the combination to form a multisensory cue, the impact would be higher due to the effect on all the senses. As a multisensory cue can affect consumer behaviours positively (Morrison et al., 2011; Hultén, 2012), time spent is superior for a multisensory cue than for single cues (Helmefalk and Hultén, 2017; Spence et al., 2014). Therefore:

$\mathrm{H}_{1 \mathrm{a}}$ - When evaluating single (visual, auditory and olfactory) and multisensory cues, the multisensory cue will provide the greatest impact on time spent.

To assess product quality, consumers use extrinsic cues, but when these cues do not exist, haptic cues are used (Abhishek et al., 2013). Research shows that single cues have the potential to impact product touching (Spence et al., 2014), and involving more senses has been shown to have a stronger influence on consumer behaviours (McCabe and Nowlis, 2003). Multisensory stimulation encourages consumers to explore the setting and the product, thus touching more (Hultén, 2012), leading to the formulation of $\mathrm{H}_{2}$ :

$\mathrm{H}_{1 \mathrm{~b}}$ - When evaluating single (visual, auditory and olfactory) and multisensory cues, the multisensory cue will have the greatest impact on touching. 
Single cues have been investigated to determine their effect on product purchasing (Krishna, 2013), with scent (Guéguen and Petr, 2006) and in-store lighting impacting purchasing (Summers and Hebert, 2001). As purchasing is the outcome of sensory cues, it is suggested that a multisensory cue is able to increase the likelihood of this action (Krishna, 2012). While single cues impact purchasing (Helmefalk and Hultén, 2017; Sherman et al., 1997; Turley and Milliman, 2000), the effect of a multisensory cue will be larger. Thus, the following four hypotheses are developed:

$\mathrm{H}_{2 \mathrm{a}}$ - A multisensory cue, comprising one visual, auditory and olfactory cue will have a positive impact on purchasing.

$\mathrm{H}_{2 \mathrm{~b}}-\mathrm{A}$ visual cue (aesthetics) will have a positive impact on purchasing.

$\mathrm{H}_{2 \mathrm{c}}-$ An auditory cue (music) will have a positive impact on purchasing.

$\mathrm{H}_{2 \mathrm{~d}}-$ An olfactory cue (scent) will have a positive impact on purchasing.

\section{Method}

Many sensory marketing studies are conducted in laboratory settings (see Turley and Milliman, 2000; Spence et al., 2014), which eliminate confounding variables and external marketing influences. As they do not represent real-life behaviours of consumers, they can reflect behavioural bias (Chandon et al., 2005; Howitt and Cramer, 2008), which is reduced in a field experimental design (Gneezy, 2017).

\section{Field experiment design}

A between subjects' field experimental design was employed to investigate $\mathrm{H}_{1-2}$ using congruent cues concerning the store image, surroundings and product, utilising individual cues and a multisensory cue, which was compared to the normal conditions and served as a control. The experiments were conducted over a 12-week period inside and adjacent to a lighting department in a leading furniture and décor store in Sweden that stocks lights, LED bulbs and lamp accessories. This shop is a leading brand in this category and is frequented extensively when purchasing décor products. Lighting products were deemed suitable to investigate these cues as they are viewed as primarily providing utilitarian value to consumers.

The setting included shelves and sampling apparatus comprising buttons and small boxes in which consumers can sample various LED light bulbs. Next to the shelves, there were various armatures and boxes for pickup within arm-length, facilitating various touching behaviours. The chosen setting was mostly white and considered lacking auditory and olfactory cues. 


\section{Cues used in the study}

Congruency between the cues was established with pre-tests in focus groups (blank for review), which considered three keywords when determining congruent cues in the specific retail setting: homely, cosy and calmness. An experiment was conducted to test several sensory cues, with the three most effective ones selected for the study (blank for review). These cues - visual, auditory and olfactory - were then grouped and installed together in an experimental condition, and the time spent, touching and purchasing were measured. Although there are other relevant cues to consider in retail settings, such as lighting and temperature (Quartier et al., 2009; Turley and Milliman, 2000), this study employed aesthetics, music, and scents as these have shown in literature to positively impact consumer behaviours (Jang et al., 2018; Mattila and Wirtz, 2001; Oakes, 2007; Tilburg et al., 2015; Vieira, 2010). For instance, regarding lighting, the experiments were already conducted in a lighting department and adding additional lighting cues could evoke sensory overload. Regarding temperature, there would be difficulties in establishing congruency and maintaining the temperature in the specific retail setting.

Visual cues comprised two red curtains $(3.0 \mathrm{~m} \times 1.5 \mathrm{~m})$ that were cut and hung over the product shelf to resemble a window. Red is regarded as a warm colour (Bellizzi and Hite, 1992) and was selected to create a homely feeling in the retail store. Plants were also placed beneath the window to enhance the concept of home. The auditory condition employed a hidden 13-watt wireless speaker, playing jazz (112 beats per minute) controlled by an MP3 player containing a playlist of jazz songs at an appropriate volume. For the olfactory condition, a scent diffuser was installed and hidden, which dispersed fragrance at a low level of concentration. The intensity of sensory cues was established as almost unnoticeable to disturb the purchasing processes (see Dijksterhuis et al., 2005). For the multisensory condition, all these previously mentioned conditions were installed simultaneously. The reason for choosing aesthetics as the visual cue, music as the auditory cue and scent as the olfactory cue is threefold. Firstly, the chosen cues have evident support in literature for having a positive impact on consumer behaviour (Hultén, 2015; Spence et al., 2014). Secondly, they were considered appropriate for the given setting as determined in focus groups. Aesthetics, scent and music were deemed by the focus group participants as missing in the specific setting and were easily installed without extensively modifying the present and surrounding settings.

The sample and data gathering group included a convenience sample of 593 observations, comprising the control condition $(n=147)$, the visual condition $(n=100)$, the auditory 
condition $(n=115)$, the olfactory condition $(n=122)$, and the multisensory condition (MS) ( $n$ $=109$ ). The criteria for inclusion were that consumers went into the experimental area and did not seek help from employees as this took a greater amount of time; hence, they were treated as outliers. The demographic variables that were gathered were gender (male/female), age (18$24,25-44,45-64$, or 65+) and number in groups (alone, $+1,+2$ and $3+$ ). See Table 1 for more information on frequencies.

Table 1 Frequencies in the various experimental conditions

\begin{tabular}{|c|c|c|c|c|c|c|}
\hline \multicolumn{7}{|c|}{ Experimental condition } \\
\hline & Control & Olfactory & Visual & Auditory & MS & Total \\
\hline \multicolumn{7}{|c|}{ Gender } \\
\hline M & 62 & 70 & 59 & 50 & 51 & 292 \\
\hline $\mathrm{F}$ & 85 & 50 & 40 & 65 & 57 & 297 \\
\hline Total & 147 & 120 & 99 & 115 & 108 & 589 \\
\hline \multicolumn{7}{|l|}{ Age } \\
\hline $18-24$ & 7 & 19 & 12 & 14 & 7 & 59 \\
\hline $25-44$ & 56 & 38 & 33 & 40 & 30 & 197 \\
\hline $45-64$ & 71 & 43 & 34 & 31 & 42 & 221 \\
\hline $65+$ & 11 & 19 & 19 & 30 & 30 & 109 \\
\hline Total & 146 & 121 & 99 & 115 & 109 & 586 \\
\hline \multicolumn{7}{|l|}{ Group } \\
\hline Alone & 55 & 39 & 50 & 46 & 29 & 219 \\
\hline+1 & 72 & 71 & 44 & 64 & 65 & 316 \\
\hline+2 & 13 & 7 & 2 & 4 & 13 & 39 \\
\hline $3+$ & 7 & 5 & 4 & 1 & 2 & 19 \\
\hline Total & 147 & 122 & 100 & 115 & 109 & 593 \\
\hline
\end{tabular}

Note: Missing values contributed to the unequal total numbers presented in the table

To address the validity, a sample was gathered (post-control) to determine the effect of extraneous variables like seasonal factors on the findings. There were no such differences found $\left(M D_{\text {control vs post-control }}=10.0, p=0.37\right)$. The demographic variables were also checked for interference; age, gender, and number in groups (see table 1). Additionally, marketing campaigns were also tracked during data gathering to exclude promotional influences.

\section{Measurements and apparatus}

The observations utilised prior objective measures (see Areni and Kim; Hoyer, 1984; Hultén, 2012) to determine the dependent variables, namely time spent (seconds, continuous), touching (seconds, continuous) and purchasing (dichotomous). Time spent was the time consumers 
passed in the setting from the moment they entered to when they left. To be of theoretical and practical value, evaluating time spent needs to be comparable under similar conditions before cues being inserted or removed (Krishna, 2012; Spence et al., 2014). Touching was gathered by determining actions using consumers' hands, such as moving products. Purchasing was measured by observing whether participants took the goods with them, putting them in the shopping basket, or not, as in Hultén (2012). As these measures are objective, there was no need for reliability measures (Alpha values or factor analysis), but a post-control study was conducted to ensure their consistency. Control variables, such as age, gender and number of shoppers, were investigated for potential impact.

\section{Procedures}

Consumers were observed from a distance and were not interrupted until they left the experimental area (see Appendix 1 for the observation scheme) when they were approached and asked to fill out a survey (including a manipulation check). Ten observers were hired and carefully instructed and supervised to follow the procedures. Statistical analysis was conducted at the $95 \%$ confidence interval.

\section{Manipulation check}

To ensure validity in experiments, manipulations checks are required (Khan, 2011; Perdue and Summers, 1986). These were gathered with a self-administrated survey, consisting of a 7-point single scale item "Did you notice any (depending on sensory condition) in the section over there?" (yes or no). The majority of the subjects did notice the sensory cues [olfactory 65\% (yes), visual $49 \%$ (yes), auditory $75 \%$ (yes), multisensory $60 \%$ (yes)]. This indicates that the manipulation checks were successful. These were then confirmed to be non-significant (using a t-test) regarding time spent $(p=0.510)$, touching $(p=0.668)$ and it is argued that they represent the larger dataset. To check for normality for the ANOVA, skewness was verified for time spent and touching, which were within the acceptable threshold of -2 and +2 (George and Mallery, 2010). The kurtosis was slightly skewed for time spent and touching $(K=3.13)$, but this is unproblematic as a one-way ANOVA is a robust test against the normality assumption (Hair et al., 2006).

\section{Results}

As the dataset had a different number of samples, these were required to be within a similar number for the ANOVA analysis (Hair et al., 2006). Therefore, a random non-significantly different subset of 110 samples were extracted from 411 in the multisensory dataset. 
Demographic (control) variables, such as age, gender and number of shoppers, were investigated for potential impact, but no instances thereof were found and no normality issues were identified.

\section{The influence of cues on time spent and touching}

A one-way between subjects' ANOVA was conducted to compare the effect of the single sensory cues (visual, auditory and olfactory cues) on time spent $\left(\mathrm{H}_{1 \mathrm{a}}\right)$ and touch $\left(\mathrm{H}_{1 \mathrm{~b}}\right)$ in the multisensory and control conditions.

In the case of $\mathrm{H}_{1 \mathrm{a}}$, there was a significant effect of the sensory cues (IV) on the time spent (DV) for the five conditions $[F(4,585)=16.12, p=0.000]$, with at least one significant difference in mean values between the five conditions. A post-hoc test compared the single cues to the multisensory condition and shows that a multisensory cue had the highest impact on time spent $\left(\mathrm{H}_{1 \mathrm{a}}\right)$. It shows the mean differences for time spent between the single sensory cues and the multisensory condition were significantly different, thus confirming $\mathrm{H}_{1 \mathrm{a}}$ (see Table 2). Auditory cues also have a strong influence, encouraging consumers to stay longer, although not as long as the multisensory condition - a difference of 28 seconds $\left(M D_{\text {auditory vs multisensory }}=27.77, S E=\right.$ 9.76, $p=0.046, \delta=0.33)$.

Table 2 Single cues vs the multisensory group

\begin{tabular}{|c|c|c|c|c|c|}
\hline \multirow[b]{2}{*}{$\begin{array}{l}\text { Sensory } \\
\text { cues }\end{array}$} & \multirow[b]{2}{*}{ Visual } & \multicolumn{4}{|c|}{ Experimental conditions } \\
\hline & & Auditory & Olfactory & $\begin{array}{l}\text { Multi- } \\
\text { sensory }\end{array}$ & $\boldsymbol{F} \quad \boldsymbol{\eta} 2$ \\
\hline Time spent & $\begin{array}{l}\mathrm{MD}=61.05 * * * \\
(\mathrm{SE}=10.07)\end{array}$ & $\begin{array}{c}\mathrm{MD}=27.77 * \\
(\mathrm{SE}=9.76)\end{array}$ & $\begin{array}{c}\mathrm{MD}=40.21 * * * \\
\quad(\mathrm{SE}=9.58)\end{array}$ & - & 16.2 .01 \\
\hline
\end{tabular}

Notes: SE appears in parentheses below the mean differences. ${ }^{*} p<0.05$; $* * * p<0.001$ are significantly different at the $p<0.05$ level, based on Bonferroni post hoc paired comparisons when compared to multisensory condition

To further investigate time spent, a post-hoc comparison using a Bonferroni test indicated that the mean scores for the auditory condition $(M=115.87, S D=78.46)$, olfactory condition $(M=$ 103.42, $S D=71.25)$ and multisensory condition $(M=143.64, S D=87.19)$ were significantly different when compared to the control condition $(M=76.66, S D=76.20)$. Conversely, the visual condition $(M=82.59, S D=37.09)$ did not differ significantly from the control (see Table 3). All of the conditions, except for the visual condition, had a significant increase in time spent at the point of purchase. 
Table 3 All conditions vs the control

\begin{tabular}{lccccccc}
\multicolumn{7}{c}{ Experimental conditions } \\
Sensory cues & Visual & Auditory & Olfactory & Multi-sensory & Control & $\boldsymbol{F}$ & $\boldsymbol{\eta} 2$ \\
Time spent & $82.59(37.09)$ & $115.87 * * *(78.67)$ & $103.42 *(71.25)$ & $143.64 * * *(87.19)$ & $76.66(76.19)$ & 16.12 & 0.01 \\
Touching & $\mathrm{ns}$ & $\mathrm{ns}$ & $\mathrm{ns}$ & $\mathrm{ns}$ & $28.35(28.28)$ & 0.76 & 0.01
\end{tabular}

Notes: SD appears in parentheses below the mean values. ${ }^{*} p<0.05$; $* * *<<0.001$ are significantly different at the $p<0.05$ level, based on Bonferroni post hoc paired comparisons when compared to control

Table III All conditions vs the control

Instead, the weakest impact, or "largest" difference between the conditions on time spent is visual cues, which showed that consumers stay 61 seconds longer $\left(M D_{\text {visual vs multisensory }}=\right.$ $\left.61.05^{* * *}, S E=10.07, p=0.000, \delta=0.911\right)$ in the multisensory condition than in the visual one. Results show that multisensory cues encouraged consumers to stay the longest in comparison to the single cues.

For $\mathrm{H}_{1 \mathrm{~b}}$, there was no significant effect of the sensory cues on touching for the five conditions $[F(4,450)=0.76, p=0.553]$. Hence, there is no difference between the groups, which subsequently rejects $\mathrm{H}_{2}$, as touching is not influenced by either the sensory or multisensory cues.

Together, these results show that multisensory cues were superior in encouraging consumers to stay longer, confirming $\mathrm{H}_{1 \mathrm{a}}$, while not being able to confirm touching more, rejecting $\mathrm{H}_{1 \mathrm{~b}}$ in the process.

\section{The influence of cues on purchasing}

To investigate how the groups compared regarding actual purchasing (dichotomous), a multiple logistic regression model was employed to test hypotheses $\mathrm{H}_{2 \mathrm{a}}-\mathrm{H}_{2 \mathrm{~d}}$, namely to examine a multisensory cue as well as visual, auditory and olfactory cues as predictors of purchasing. A test of the full model against a constant only model was statistically significant $\left(\mathrm{X}^{2}=24.73, p\right.$ $<0.001$ with $d f=4)$. Nagelkerke's $\mathrm{R}^{2}$ of 0.056 indicated a weak relationship between prediction and grouping. This can be partly explained by the field experimental design, which Mattila and Wirtz (2001, p. 285) state can reflect on the effects or "model fit". Prediction overall was 64\% ( $87.8 \%$ for No and $27.9 \%$ for Yes), yet the Wald criterion showed that only multisensory cues significantly influenced purchase $(p=0.000)$. Visual, auditory and olfactory cues were not significant predictors when multisensory cues were included. The $\operatorname{Exp}(B)$ value, namely the 
odds ratio, indicates that when multisensory cues are raised by one unit (the inclusion of multisensory cues in comparison to the other conditions), the odds ratio is three times as large. Therefore, consumers are three times more likely to purchase in that condition than the other. While the model does not provide good fit, it clearly proves that purchase is influenced in the condition of multisensory cues and rejects the others. This consequently confirms the impact of the multisensory cue $\mathrm{H}_{2 \mathrm{a}}$ and rejects the single cues in $\mathrm{H}_{2 \mathrm{~b}}-\mathrm{H}_{2 \mathrm{~d}}$.

Table 4 Sensory cues and the odds of purchase in comparison to each other

\begin{tabular}{lccccc}
\hline \multicolumn{7}{c}{ Multiple logistic regression } \\
Cues & $\boldsymbol{B}$ & SE & Wald & df & $\operatorname{Exp}(\boldsymbol{B})(\mathbf{9 5 \%} \mathbf{C I})$ \\
Multisensory $(H 3 a)$ & $1.16^{* * *}$ & 0.27 & 19.26 & 1 & $3.19(1.90,5.36)$ \\
Visual $(H 3 b)$ & 0.34 & 0.27 & 1.56 & 1 & $1.40(0.83,2.39)$ \\
Auditory $(H 3 c)$ & 0.19 & 0.26 & 0.55 & 1 & $1.22(0.73,2.04)$ \\
Olfactory $(H 3 d)$ & 0.04 & 0.26 & 0.027 & 1 & $1.04(0.62,1.75)$
\end{tabular}

Notes: Lower and upper confidence intervals are presented next to the odds ratio $\operatorname{Exp}(B) . * * * p<0.001$ are significantly different at the $p<0.05$ level

Together, the results show that multisensory cues are superior to time spent and, regarding the odds of purchase $\mathrm{H}_{1 \mathrm{a}}$ and $\mathrm{H} 2_{\mathrm{a}}$, no linear or mediating relationship between these concepts was identified.

\section{Discussion}

The purpose of this research was to investigate the impact of a multisensory cue - formed through the combination of single cues - on consumer behaviours in a retail context, and the findings show that multisensory cues have higher scores when it comes to time spent and purchasing, resulting in support for $\mathrm{H}_{1 \mathrm{a}}$ and $\mathrm{H}_{2 \mathrm{a}}$.

While Spence et al. (2014) highlight the importance of multisensory retail settings for consumer emotions and behaviours, Spangenberg et al. (2005) state that the interactive effects of environmental stimuli are not well understood. Hence, the results of this present research contribute and confirm that purchasing behaviours in real purchasing situations are affected by a multisensory cue comprising of three sensory cues. The purchasing behaviours that were influenced were time spent and purchasing, although it was not determined which of the threecue combinations (for example, visual-tactile, visual-auditory and other) impacted consumers' time spent and purchasing. These findings show that the effect is sufficient to consider 
modifying the retail atmosphere to be multisensory to influence the time consumers spend in a retail setting and purchasing.

Further, it is still sufficient to alter single cues to have an impact on time spent (Hultén, 2015; Krishna, 2012; Spence et al., 2014). For instance, auditory cues had the second largest mean value of 116 seconds in comparison to the normal state, which had 77 seconds. The secondbest single cue for increasing time spent was by infusing setting-congruent scents with a value of 103 seconds, which supports the findings into the effect of scent of Kivioja (2017). Despite the dominance of visual cues, these were not significant in comparison to the control condition regarding time spent. This can be ascribed to employing a similar type of sensory cue (visual cues in a lighting department) that becomes overloaded. As it is not optimally stimulated (e.g. Jang et al., 2018; Raju, 1980), it does not contribute significantly to the holistic experience. This study confirms that it is sufficient to add a single cue that complements the retail setting (Abhishek et al., 2013; Herrmann et al., 2013; Hinks and Shamey, 2011; Michel et al., 2017), but also shows that including more senses (that is, multisensory cues) is more beneficial for influencing consumer behaviour. As Spence et al. (2014) discuss the potential impact of multisensory cues on behaviours, this research paper shows the superior impact of multisensory cues (over single cues) on time spent (144 seconds) and purchasing. In contrast to previous literature (Helmefalk and Hultén, 2017), these findings actually demonstrate that combining three cues, making them multisensory, impacts superiorly on consumer behaviours, which signify that a retail store that stimulates more senses, provides a more holistic experience (Imschloss and Kuehnl, 2017; Mattila and Wirtz, 2001; Spangenberg et al., 2005), hence facilitates in-store purchasing.

With respect to purchasing, the results show that the multisensory cue had a significant impact on purchasing $\left(\mathrm{H}_{2 \mathrm{a}}\right)$. Consumers were up to three times more disposed to purchase in the multisensory condition than in the other conditions. A multisensory cue stimulates purchasing as customers perceive more information, clearer order, structure and pleasure, which influences their behaviour (Hekkert, 2006).

Contrary to expectations, this study did not find a significant effect of cues on touching in any of the sensory conditions. A possible explanation for this could be the product category of lighting products (McCabe and Nowlis, 2003), which does not encourage touching or adequate extrinsic cues were available (Abhishek et al., 2013), eliminating the NFT.

This article shows that multisensory modified retail settings encourage consumers to stay longer and purchase more, but not to increase touching (of the product). While modifying single cues 
has also been shown to impact consumer behaviours, it is not to the extent of the multisensory condition.

\section{Theoretical and managerial implications}

Theoretically, these findings highlight the importance of a multisensory cue in the retail context to affect time spent and touching due to the implementation of congruent single cues. While this study did not confirm the touching hypothesis, it supports the view that touch is not equally important for all product categories (McCabe and Nowlis, 2003) and adds opportunities for further inquiry.

Practically, when retailers modify a store setting to be more inviting or to stimulate purchasing, use is made of established tools shared among corporations, or of heuristic gut feelings (Gigerenzer and Gaissmaier, 2011). This study shows that single cues integrated to form a congruent multisensory cue result in positive effects (Hekkert, 2006). While adjusting a single cue like music or scent, it has been shown to have a significant effect on consumers in terms of time spent and purchasing, but the effect of the multisensory condition exceeds that of single cues, even at low levels of intensity. Incorporation of product-appropriate multisensory cues can benefit retailers, as consumers are prone to stay much longer and there is an increased likelihood of purchasing products.

\section{Limitations and further research}

The present study has various limitations. Firstly, it was impractical to conduct experiments in 10 conditions investigating single cue interactions (Ballantine et al., 2010). Further, the research was conducted focusing on one product category and the findings cannot be generalised due to the study being conducted in a specific retail context and focusing on a particular product category in Sweden. The results are also specific to this type of retailer that stocks products other than lighting products, thus similar effects may not be noted in other lighting retailers.

There are various opportunities for further research associated with this study. Although this paper focused on multisensory cues, it must also be noted that the findings cannot be fully generalised to all brands, retail stores and product sections, as this requires establishing their own congruent sensory cues. Therefore, replication of this research paper in another retail context, such as a restaurant, is suggested, where other cues (like taste) can be similarly evaluated. While taste cues were impractical to install in the examined setting, it would be of interest to investigate whether this additional cue provides more information (Marks, 2014) and 
facilitates purchasing (Krishna, 2012). Alternatively, as demonstrated in this study, touching was not affected by the external stimuli in the lighting department of a furniture retailer. Further research into the role of the product category (McCabe and Nowlis, 2003) as well NFT (Peck and Childers, 2003) as mediators in the multisensory conditions is necessary. Using a real shopping situation, it was not possible to determine the effect of psychological or sociological concepts through objective measures (fMRI, brain scanning), but investigation into these aspects in a multisensory condition is suggested. While the findings are significant, potential moderators or mediators may exist that could expand the current findings. Concepts that can potentially explain or moderate the relationships in this study include planned purchasing, brand loyalty and motivational orientations (see sources). Future research is recommended to examine these.

\section{Conclusion}

This article assesses the importance of a congruent multisensory cue in a retail shopping context and shows this condition has a greater impact on consumer behaviours, specifically time spent and the likelihood of purchasing, than singles cues. The inclusion of multisensory cues within retail settings has thus been proven to be beneficial to retailers.

\section{References}

Abhishek, S., Sinha, P. K. and Vohra, N. (2013), "Role of haptic touch in shopping". Decision, Vol. 40 No. 3, pp. 153-163.

Antick, J. R. and Schandler, S. L. (1993), “An exploration of the interaction between variation in wavelength and time perception". Perceptual and motor skills, Vol. 76 No. 3, pp. 987-994. Areni, C. S. and Kim, D. (1993). The influence of background music on shopping behavior: classical versus top-forty music in a wine store. Provo, UT. McAlister, L. and Rothschild, M.L. (Eds.), NA - Advances in Consumer Research Volume 20, Association for Consumer Research, pp. 336-340.

Ballantine, P. W., Jack, R. and Parsons, A. G. (2010), “Atmospheric cues and their effect on the hedonic retail experience". International Journal of Retail \& Distribution Management, Vol. 38 No. 8, pp. 641-653.

Bellizzi, J. A. and Hite, R. E. (1992), "Environmental color, consumer feelings, and purchase likelihood". Psychology \& Marketing, Vol. 9 No. 5, pp. 347-363. 
Bloch, P. H., Ridgway, N. M. and Sherrell, D. L. (1989), "Extending the concept of shopping: An investigation of browsing activity". Journal of the Academy of Marketing Science, Vol. 17 No. 1, pp. 13-21.

Chandon, P., Morwitz, V. G. and Reinartz, W. J. (2005), "Do intentions really predict behavior? Self-generated validity effects in survey research". Journal of Marketing, Vol. 69 No. 2, pp. 114.

Chebat, J.-C. and Michon, R. (2003), "Impact of ambient odors on mall shoppers' emotions, cognition, and spending: a test of competitive causal theories". Journal of Business Research, Vol. 56 No. 7, pp. 529-539.

Clement, J. (2007), "Visual influence on in-store buying decisions: an eye-track experiment on the visual influence of packaging design". Journal of Marketing Management, Vol. 23 No. 910, pp. 917-928.

Crisinel, A. S., Jacquier, C., Deroy, O. and Spence, C. (2013), "Composing with Cross-modal Correspondences: Music and Odors in Concert”. Chemosensory Perception, Vol. 6 No. 1, pp. 45-52.

Custers, P. J. M., De Kort, Y. a. W., Ijsselsteijn, W. A. and De Kruiff, M. E. (2010), "Lighting in retail environments: Atmosphere perception in the real world". Lighting Research and Technology, Vol. 42 No. 3, pp. 331-343.

Demoulin, N. (2011), "Music congruency in a service setting: The mediating role of emotional and cognitive responses". Journal of Retailing and Consumer Services, Vol. 18 No. 1, pp. 1018.

Deroy, O. and Valentin, D. (2011), "Tasting liquid shapes: investigating the sensory basis of cross-modal correspondences". Chemosensory Perception, Vol. 4 No. 3, pp. 80-90.

Dijksterhuis, A., Smith, P. K., Van Baaren, R. B. and Wigboldus, D. H. (2005), "The unconscious consumer: Effects of environment on consumer behavior". Journal of Consumer Psychology, Vol. 15 No. 3, pp. 193-202.

Donovan, R. J., Rossiter, J. R., Marcoolyn, G. and Nesdale, A. (1994), "Store atmosphere and purchasing behavior”. Journal of Retailing, Vol. 70 No. 3, pp. 283-294.

Dube, L. and Morin, S. (2001), "Background music pleasure and store evaluation Intensity effects and psychological mechanisms". Journal of Business Research, Vol. 54 No. 2, pp. 107113.

George, D. and Mallery, P. 2010. SPSS for Windows step by step. A simple study guide and reference (10. Bask1). Boston, MA: Pearson Education, Inc. 
Gigerenzer, G. and Gaissmaier, W. (2011), "Heuristic decision making”. Annual review of psychology, Vol. 62 No. pp. 451-482.

Gneezy, A. (2017), "Field experimentation in marketing research". Journal of Marketing Research, Vol. 54 No. 1, pp. 140-143.

Grohmann, B., Spangenberg, E. R. and Sprott, D. E. (2007), "The influence of tactile input on the evaluation of retail product offerings". Journal of Retailing, Vol. 83 No. 2, pp. 237-245.

Guéguen, N. and Petr, C. (2006), “Odors and consumer behavior in a restaurant”. International Journal of Hospitality Management, Vol. 25 No. 2, pp. 335-339.

Hair, J. F., Black, W. C., Babin, B. J., Anderson, R. E. and Tatham, R. L. (2006), Multivariate data analysis 6th Edition, New Jersey: Pearson Education.

Hekkert, P. (2006), "Design aesthetics: principles of pleasure in design". Psychology Science, Vol. 48 No. 2, pp. 157-172.

Helmefalk, M. (2016), “Congruency as a mediator in an IKEA retail setting: products, services and store image in relation to sensory cues". International Journal of Retail \& Distribution Management, Vol. 44 No. 9, pp. 956-972.

Helmefalk, M. and Hultén, B. (2017), "Multi-sensory congruent cues in designing retail store atmosphere: Effects on shoppers' emotions and purchase behavior". Journal of Retailing and Consumer Services, Vol. 38 No. pp. 1-11.

Herrmann, A., Zidansek, M., Sprott, D. E. and Spangenberg, E. R. (2013), “The power of simplicity: processing fluency and the effects of olfactory cues on retail sales". Journal of Retailing, Vol. 89 No. 1, pp. 30-43.

Hinks, D. and Shamey, R. (2011), "Review of retail store lighting: implications for colour control of products". Coloration Technology, Vol. 127 No. 2, pp. 121-128.

Howitt, D. and Cramer, D. (2008), Introduction to research methods in psychology, Harlow, Essex, England, Pearson Education.

Hoyer, W. D. (1984), “An examination of consumer decision making for a common repeat purchase product”. Journal of Consumer Research, Vol. 11 No. 3, pp. 822-829.

Hultén, B. (2011), "Sensory marketing: the multi-sensory brand-experience concept". European Business Review, Vol. 23 No. 3, pp. 256-273.

Hultén, B. (2012), "Sensory cues and shoppers' touching behaviour: the case of IKEA". International Journal of Retail \& Distribution Management, Vol. 40 No. 4, pp. 273-289.

Hultén, B. (2015), Sensory Marketing: Theoretical and Empirical Grounds, New York, Routledge. 
Imschloss, M. and Kuehnl, C. (2017), "Don't ignore the floor: Exploring multisensory atmospheric congruence between music and flooring in a retail environment". Psychology \& Marketing, Vol. 34 No. 10, pp. 931-945.

Jacob, C., Guéguen, N., Boulbry, G. and Sami, S. (2009), “Love is in the air': congruence between background music and goods in a florist". The International Review of Retail, Distribution and Consumer Research, Vol. 19 No. 1, pp. 75-79.

Jang, J. Y., Baek, E. and Choo, H. J. (2018), "Managing the visual environment of a fashion store: Effects of visual complexity and order on sensation-seeking consumers". International Journal of Retail \& Distribution Management, Vol. 46 No. 2, pp. 210-226.

Kahneman, D., Knetsch, J. L. and Thaler, R. H. (1990), "Experimental tests of the endowment effect and the Coase theorem". Journal of political Economy, Vol. 98 No. 6, pp. 1325-1348.

Khan, J. (2011), "Validation in marketing experiments revisited". Journal of Business Research, Vol. 64 No. 7, pp. 687-692.

Kivioja, K. (2017), "Impact of point-of-purchase olfactory cues on purchase behavior". Journal of Consumer Marketing, Vol. 34 No. 2, pp. 119-131.

Krishna, A. (2012), “An integrative review of sensory marketing: Engaging the senses to affect perception, judgment and behavior". Journal of Consumer Psychology, Vol. 22 No. 3, pp. 332351.

Krishna, A. (2013), Customer sense: How the 5 senses influence buying behavior, New York, Palgrave Macmillan.

Krishna, A., Elder, R. and Caldara, C. (2010), "Feminine to smell but masculine to touch? Multisensory congruence and its effect on the aesthetic experience”. Journal of Consumer Psychology, Vol. 20 No. 4, pp. 410-418.

Lowe, M. L. and Haws, K. L. (2017), "Sounds Big: The Effects of Acoustic Pitch on Product Perceptions”. Journal of Marketing Research, Vol. 52 No. 2, pp. 331-346.

Macpherson, F. (2010), The senses: Classic and contemporary philosophical perspectives, Oxford, Oxford University Press.

Marks, L. E. (2014), The unity of the senses: Interrelations among the modalities, New York, Academic Press.

Marlow, N. and Jansson-Boyd, C. V. (2011), "To touch or not to touch; that is the question. Should consumers always be encouraged to touch products, and does it always alter product perception?”. Psychology \& Marketing, Vol. 28 No. 3, pp. 256-266.

Mattila, A. S. and Wirtz, J. (2001), “Congruency of scent and music as a driver of in-store evaluations and behavior". Journal of Retailing, Vol. 77 No. 2, pp. 273-289. 
Mccabe, D. B. and Nowlis, S. M. (2003), “The effect of examining actual products or product descriptions on consumer preference". Journal of Consumer Psychology, Vol. 13 No. 4, pp. 431-439.

Michel, A., Baumann, C. and Gayer, L. (2017), “Thank you for the music-or not? The effects of in-store music in service settings". Journal of Retailing and Consumer Services, Vol. 36 No. pp. 21-32.

Morrin, M. and Ratneshwar, S. (2000), “The impact of ambient scent on evaluation, attention, and memory for familiar and unfamiliar brands". Journal of Business Research, Vol. 49 No. 2, pp. 157-165.

Morrison, M., Gan, S., Dubelaar, C. and Oppewal, H. (2011), "In-store music and aroma influences on shopper behavior and satisfaction". Journal of Business Research, Vol. 64 No. 6, pp. 558-564.

Oakes, S. (2007), "Evaluating empirical research into music in advertising: A congruity perspective". Journal of Advertising Research, Vol. 47 No. 1, pp. 38-50.

Parsons, A. G. (2009), "Use of scent in a naturally odourless store”. International Journal of Retail \& Distribution Management, Vol. 37 No. 5, pp. 440-452.

Peck, J. and Childers, T. L. (2003), "Individual differences in haptic information processing: The "need for touch" scale". Journal of Consumer Research, Vol. 30 No. 3, pp. 430-442.

Peck, J. and Childers, T. L. (2006), "If I touch it I have to have it: Individual and environmental influences on impulse purchasing”. Journal of Business Research, Vol. 59 No. 6, pp. 765-769. Peck, J. and Shu, S. B. (2009), “The effect of mere touch on perceived ownership". Journal of Consumer Research, Vol. 36 No. 3, pp. 434-447.

Perdue, B. C. and Summers, J. O. (1986), “Checking the success of manipulations in marketing experiments". Journal of Marketing Research, Vol. 23 No. 4, pp. 317-326.

Quartier, K., Christiaans, H. and Van Cleempoel, K. 2009. Retail design: lighting as an atmospheric tool, creating experiences which influence consumers' mood and behaviour in commercial spaces. Undisciplined! Proceedings of the Design Research Society Conference 2008. Sheffield Hallam University, Sheffield, UK.

Raju, P. S. (1980), “Optimum stimulation level: Its relationship to personality, demographics, and exploratory behavior". Journal of Consumer Research, Vol. 7 No. 3, pp. 272-282.

Ramachandran, V. S. and Brang, D. (2008), “Tactile-emotion synesthesia”. Neurocase, Vol. 14 No. 5, pp. 390-399. 
Sherman, E., Mathur, A. and Smith, R. B. (1997), "Store environment and consumer purchase behavior: mediating role of consumer emotions". Psychology \& Marketing, Vol. 14 No. 4, pp. 361-378.

Skandrani, H., Mouelhi, N. B. D. and Malek, F. (2011), "Effect of store atmospherics on employees' reactions". International Journal of Retail \& Distribution Management, Vol. 39 No. 1, pp. 51-67.

Spangenberg, E. R., Grohmann, B. and Sprott, D. E. (2005), “It's beginning to smell (and sound) a lot like Christmas: the interactive effects of ambient scent and music in a retail setting". Journal of Business Research, Vol. 58 No. 11, pp. 1583-1589.

Spangenberg, E. R., Sprott, D. E., Grohmann, B. and Tracy, D. L. (2006), “Gender-congruent ambient scent influences on approach and avoidance behaviors in a retail store". Journal of Business Research, Vol. 59 No. 12, pp. 1281-1287.

Spence, C. and Gallace, A. (2011), "Tasting shapes and words". Food Quality and Preference, Vol. 22 No. 3, pp. 290-295.

Spence, C., Puccinelli, N. M., Grewal, D. and Roggeveen, A. L. (2014), "Store Atmospherics: A Multisensory Perspective". Psychology \& Marketing, Vol. 31 No. 7, pp. 472-488.

Streicher, M. C. and Estes, Z. (2016), "Multisensory interaction in product choice: Grasping a product affects choice of other seen products". Journal of Consumer Psychology, Vol. 26 No. 4, pp. 558-565.

Summers, T. A. and Hebert, P. R. (2001), "Shedding some light on store atmospherics: influence of illumination on consumer behavior". Journal of Business Research, Vol. 54 No. 2, pp. 145-150.

Tilburg, M., Lieven, T., Herrmann, A. and Townsend, C. (2015), "Beyond "Pink It and Shrink It” Perceived Product Gender, Aesthetics, and Product Evaluation”. Psychology \& Marketing, Vol. 32 No. 4, pp. 422-437.

Turley, L. W. and Milliman, R. E. (2000), “Atmospheric effects on shopping behavior: a review of the experimental evidence". Journal of Business Research, Vol. 49 No. 2, pp. 193-211.

Van Kerrebroeck, H., Willems, K. and Brengman, M. (2017), “Touching the void: Exploring consumer perspectives on touch-enabling technologies in online retailing". International Journal of Retail \& Distribution Management, Vol. 45 No. 7/8, pp. 892-909.

Vieira, V. A. (2010), "Visual aesthetics in store environment and its moderating role on consumer intention". Journal of Consumer Behaviour, Vol. 9 No. 5, pp. 364-380.

Vieira, V. A. (2013), "Stimuli-organism-response framework: A meta-analytic review in the store environment”. Journal of Business Research, Vol. 66 No. 9, pp. 1420-1426. 
Wiener, H. J. D. and Chartrand, T. L. (2014), “The Effect of Voice Quality on Ad Efficacy”. Psychology \& Marketing, Vol. 31 No. 7, pp. 509-517.

Williams, L. and Ackerman, J. 2011. Please Touch the Merchandise [Online]. Harvard

Business Review: HBR. Available: https://hbr.org/2011/12/please-touch-the-merchandise [Accessed 6 July 2018]. 


\section{Appendix 1}

\section{Observational scheme}

\section{Observations}

\section{Control variables}

- Age: $0-6,7-17, \quad 18-24,25-44,45-64,65+$

- Gender:

Male

Female

- Number in group: $+1,+2$ or $3+$

\section{DV}

- Looked at the POP

Yes I

No

- $\quad$ Time spent at the POP (seconds) =

- Time spent touching at the POP (seconds) =

- Bought something at the POP? Yes

No

\section{Survey}

Manipulation check, modified for each condition:

- Did you notice, feel, sense (the curtains, light, colour, illumination, music, background sounds, scents) in the section over there?

Yes I No

